\title{
Changes in Blood Pressure and Heart Rate Measurement Undergraduate Students During Exam Period
}

\author{
Senol Dogan*, Nilay Nalcaci, Serkan Dogan, Almir Badnjevic, Amina Kurtovic and Damir Marjanovic \\ International Burch University, Genetics and Bioengineering Department, Bosnia and Herzegovina
}

\begin{abstract}
Stress is a part of human life, especially for urban citizens. Stress is inseparable characteristics of student life, especially exam days. Stress management is one of the first steps which can affect students success during the exams, especially in universities. Blood pressure is the first stress observation symptom to understand its level. Therefore, to understand the stress impact of university students during the exam weeks, a conditional experiment has been designed. 200 students were selected from Bosnian and Turkish female and male. The students' blood systolic, diastolic and heart rate were measured to detect the differences between non-exams days and exam days. The blood pressure measurement has been done 3 times in specific times, non-exam days, midterm and final days. Since non-exam days were taken as stress off days, they were supposed that these days were control data to compare with exam days to see the differences. As a result of the measurements, Bosnian females showed the highest increasing, systolic $13.2 \%$, diastolic $9.3 \%$ and heart rate $8.5 \%$ during the midterm exam days. The group has been followed by Bosnian males, systolic $6.9 \%$, diastolic $6.1 \%$ and heart rate 6.63 increased during the midterm days. Although Turkish students blood pressure and heart rate increased, the values were less than Bosnian students. Moreover, high correlation significance results belonged to Bosnian females and males, 0.722 and 0.698 respectively. Finally, it was concluded that if students have scholarship they have more blood pressure during the exams. While $95 \%$ of Bosnian females and $90 \%$ of Bosnian males have some scholarship, no Turkish students have scholarship demonstrated the differences between Bosnian and Turkish students blood measurements.
\end{abstract}

Keywords: Blood pressure; Stress; Bosnian females and males; Statistical observations

\section{Introduction}

Blood pressure measures the pressure of circulating blood in blood vessels. The inner walls of the blood vessels are affected by the pressure and it is measured by sphygmomanometer. If the diastolic pressure is more than $140 \mathrm{~mm} / \mathrm{Hg}$ and systolic pressure is more than $80 \mathrm{~mm} / \mathrm{Hg}$, it is considered to be an abnormal blood pressure [1]. Physiological problems and unbalanced nourishment may disrupt the homeostasis of the blood. In addition to that, stress is another main source of high blood pressure. It is quite obvious that any form of stress is defined to produce mental and physiological reactions in the body and alternate the heart rate and blood pressure [2]. Although some extent stress is helpful in coping with problems, too much of it can affect the performance negatively [3]. The basic definition of stress is anxiety which lets the brain prepares the body for defensive actions the fight or flight response by releasing of cortisone and adrenaline hormones [4]. Getting an external sense, memorizing the events and thinking about potential upcoming problems increase the activity of hypothalamic-pituitary-adrenocortical (HPA) axis which circulates the levels of glucocorticoids, vasoconstriction hormones $[5,6]$. The axis consists of sympathetic actions that affect heart rate, blood pressure, depth of respiration, body balance, temperature and skin resistance [6]. The hormones cause various physiological alterations and the heart starts to pump faster in order to supply the body's muscles with a larger supply of oxygen, the diameter of the blood vessels contracts, the body perspires more to prevent over-heating and finally most of the metabolic rates increase [7]. Almost all people, especially urban citizens, are under stress. Over-work, traffic, economic uncertainty, health care are major source of stress that the people may have every day. To these types of stress sources, studentship can be added because of curriculum, academic competition, examinations. These are all enough to increase the anxiety level which causes high blood pressure and heart rate [6]. Especially university students have many task to do and examination traffics, midterm, final and make-up. It could be guessed those female students may have higher blood pressure than male students during the exam days. To understand the blood pressure and heart rate differences between non-exam days and exam days is the main aim of the research. In addition to that, the students sample groups were separated into 4 groups male/female and Bosnian/Turkish to understand the changing depending on sex or nation more. Although biostatistical and biometrics researches have been done mostly with big data and genomic analysis of gene expression, life science directly related areas need to be applied to the biostatistical application to find a correlation [8-11]. To increase the human life quality and manage the problems, stress, and daily life troubles, the things which affect our life should be developed by new statistical observations. Exam stress is one of the biggest problems for the students that they meet every year a few times $[12,13]$. The best solution to solve the problems is to observe the problems, collect data and find the statistical meaning of them.

\section{Materials and Methods}

Since the same students should be measured during the 3 specials weeks, selecting the students is the first step. Then, Bosnian Male/ Female and Turkish Male/Female 200 university students were selected as experimental groups for the research. The analyzed cohort consisted of 50 Bosnian females, 50 Bosnian males and 50 Turkish females, 50

${ }^{*}$ Corresponding author: Dogan S, International Burch University, Genetics and Bioengineering Department, Bosnia and Herzegovina, Tel: +387 33944 400; E-mail: senol1dogan3@gmail.com

\section{Received April 20, 2017; Accepted April 25, 2017; Published April 28, 2017}

Citation: Dogan S, Nalcaci N, Dogan S, Badnjevic A, Kurtovic A, et al. (2017) Changes in Blood Pressure and Heart Rate Measurement Undergraduate Students During Exam Period. J Biom Biostat 8: 347. doi: 10.4172/2155-6180.1000347

Copyright: @ 2017 Dogan S, et al. This is an open-access article distributed under the terms of the Creative Commons Attribution License, which permits unrestricted use, distribution, and reproduction in any medium, provided the original author and source are credited. 
Turkish males. The selected students confirmed to give blood pressure and heart rate measurement during the non-exam days, midterm and final exam days. This would let us observe changing of blood pressure and heart rate by measuring the same students in different times (Table 1). According to each student systolic, diastolic and heart rate values, from 1 to 50 , a table has been designed to see all values at different times, non-exam, midterm and final weeks at the same time. Then, the measurement has been started by using an electronic sphygmomanometer which presents the three data digitally. So, each data was registered and made a table for Bosnian female/male and Turkish female/male. Since each student name was known, the all data were registered precisely and the experimental table has been completed after final exams were over (Table 1). After the preparation of the table with values, it has been applied to the statistical program to reveal the significance of the data. The last measurements have been completed after the final exam week and applied to SPSS statistical program which analyzed the data in descriptive and correlation methods. SPSS gave us the four group's descriptive statistical results, minimum, maximum, mean and standard deviation of systole, diastole and heart rate during the non-exam weeks, midterm and final weeks (Table 2). After the first result, the data have been analyzed based on Pearson correlation and significance of the data is separated into 0.01 level (2-tailed) and 0.05 level (2-tailed).

\section{Results}

According to the descriptive results, each student systole, diastole and heart rate values have been analyzed during the non-exam, midterm and final weeks. The all measurement values were first analyzed by descriptive statistics and then correlation analyzing.

\section{Non-exam days}

While Bosnian and Turkish male have the highest mean in systole and diastole, $130,126.5 \mathrm{~mm} / \mathrm{Hg}$ and $80.8,76.5 \mathrm{~mm} / \mathrm{Hg}$ respectively, Turkish and Bosnian females have the highest heart rate 87.4, 82.3 during the non-exam days' (Table 2). The result is accepted as regular days blood pressure and heart rate among the four different groups. The non-exam days were taken as control data in order to reveal how the pressure and rate changing during the exam days.

\section{Midterm week}

The same measurement again has been applied to the same students during the midterm and final weeks' . The non-exam days were accepted minimum stress load, so the days were supposed as control data which were compared with exam weeks data. As a result of the data, Bosnian female's blood measurement showed the highest increasing among the four groups. Their systole, diastole and heart rate averages increased $13.2 \%, 9.3 \%$ and $8.5 \%$ during the midterm week respectively (Table 3 ). The second highest increasing group was the Bosnian male. Their systole, diastole, heart rate increased $6.9 \%, 6.1 \%$ and $6.6 \%$ during the midterm week respectively. The third blood measurement increased group was Turkish females' systole, diastole and heart rate 8.9\%, 5.3\% and $4.5 \%$ respectively. Although the all blood measurement have been increased during the midterm, Turkish males students data presented

\begin{tabular}{|c|c|c|c|c|c|c|c|c|c|c|c|c|}
\hline \multirow[b]{2}{*}{$\begin{array}{l}\text { Blood pressure. and heart } \\
\text { rate }\end{array}$} & \multicolumn{3}{|c|}{ Bosnian female } & \multicolumn{3}{|c|}{ Bosnian male } & \multicolumn{3}{|c|}{ Turkish female } & \multicolumn{3}{|c|}{ Turkish male } \\
\hline & $\begin{array}{l}\text { Non-exam } \\
\text { week }\end{array}$ & Midterm & Final & $\begin{array}{l}\text { Non-exam } \\
\text { week }\end{array}$ & Midterm & Final & $\begin{array}{l}\text { Non-exam } \\
\text { week }\end{array}$ & Midterm & Final & $\begin{array}{l}\text { Non-exam } \\
\text { week }\end{array}$ & Midterm & Final \\
\hline Student 1 systole $\mathrm{mm} / \mathrm{Hg}$ & Value 1 & Value 2 & Value 3 & Value 1 & Value 2 & Value 3 & Value 1 & Value 2 & Value 3 & Value 1 & Value 2 & Value 3 \\
\hline Student 1 diastole $\mathrm{mm} / \mathrm{Hg}$ & Value 1 & Value 2 & Value 3 & Value 1 & Value 2 & Value 3 & Value 1 & Value 2 & Value 3 & Value 1 & Value 2 & Value 3 \\
\hline Student 1 heart rate & Value 1 & Value 2 & Value 3 & Value 1 & Value 2 & Value 3 & Value 1 & Value 2 & Value 3 & Value 1 & Value 2 & Value 3 \\
\hline Student 2 systole $\mathrm{mm} / \mathrm{Hg}$ & Value 1 & Value 2 & Value 3 & Value 1 & Value 2 & Value 3 & Value 1 & Value 2 & Value 3 & Value 1 & Value 2 & Value 3 \\
\hline Student 2 diastole $\mathrm{mm} / \mathrm{Hg}$ & Value 1 & Value 2 & Value 3 & Value 1 & Value 2 & Value 3 & Value 1 & Value 2 & Value 3 & Value 1 & Value 2 & Value 3 \\
\hline Student 2 heart rate & Value 1 & Value 2 & Value 3 & Value 1 & Value 2 & Value 3 & Value 1 & Value 2 & Value 3 & Value 1 & Value 2 & Value 3 \\
\hline ...... & Value 1 & Value 2 & Value 3 & Value 1 & Value 2 & Value 3 & Value 1 & Value 2 & Value 3 & Value 1 & Value 2 & Value 3 \\
\hline$\ldots \ldots$ & Value 1 & Value 2 & Value 3 & Value 1 & Value 2 & Value 3 & Value 1 & Value 2 & Value 3 & Value 1 & Value 2 & Value 3 \\
\hline$\ldots \ldots$ & Value 1 & Value 2 & Value 3 & Value 1 & Value 2 & Value 3 & Value 1 & Value 2 & Value 3 & Value 1 & Value 2 & Value 3 \\
\hline Student 50 systole $\mathrm{mm} / \mathrm{Hg}$ & Value 1 & Value 2 & Value 3 & Value 1 & Value 2 & Value 3 & Value 1 & Value 2 & Value 3 & Value 1 & Value 2 & Value 3 \\
\hline Student 50 diastole $\mathrm{mm} / \mathrm{Hg}$ & Value 1 & Value 2 & Value 3 & Value 1 & Value 2 & Value 3 & Value 1 & Value 2 & Value 3 & Value 1 & Value 2 & Value 3 \\
\hline Student 50 heart rate & Value 1 & Value 2 & Value 3 & Value 1 & Value 2 & Value 3 & Value 1 & Value 2 & Value 3 & Value 1 & Value 2 & Value 3 \\
\hline
\end{tabular}

Table 1: Blood pressure and heart rate measurement among the 4 groups.

\begin{tabular}{|c|c|c|c|c|c|c|c|c|c|c|c|c|c|c|}
\hline Systole $_{\text {non-exam }}$ & Min & Max & Mean & Std. Dev. & Diastole $_{\text {non-exam }}$ & Min & Max & Mean & Std. Dev. & Heart rate ${ }_{\text {non-exam }}$ & Min & Max & Mean & Std. Dev. \\
\hline Bosnian female & 92.0 & 146.0 & 113.8 & 13.0 & Bosnian female & 57.0 & 88.0 & 74.9 & 8.0 & Bosnian female & 60.0 & 119.0 & 82.3 & 13.3 \\
\hline Bosnian male & 99.0 & 164.0 & 130.0 & 14.6 & Bosnian male & 61.0 & 102.0 & 80.8 & 10.2 & Bosnian male & 46.0 & 106.0 & 74.6 & 13.7 \\
\hline Turkish female & 91.0 & 138.0 & 111.9 & 12.1 & Turkish female & 59.0 & 94.0 & 75.3 & 8.0 & Turkish female & 65.0 & 119.0 & 87.4 & 12.3 \\
\hline Turkish male & 103.0 & 152.0 & 126.5 & 11.9 & Turkish male & 54.0 & 100.0 & 76.5 & 8.3 & Turkish male & 55.0 & 120.0 & 81.6 & 13.2 \\
\hline Systole $_{\text {midterm }}$ & Min & Max & Mean & Std. Dev. & Diastole $_{\text {midterm }}$ & Min & Max & Mean & Std. Dev. & Heart rate ${ }_{\text {midterm }}$ & Min & Max & Mean & Std. Dev. \\
\hline Bosnian female & 97.0 & 159.0 & 128.0 & 15.0 & Bosnian female & 61.0 & 118.0 & 81.7 & 12.2 & Bosnian female & 59.0 & 136.0 & 94.9 & 15.4 \\
\hline Bosnian male & 107.0 & 170.0 & 139.0 & 14.3 & Bosnian male & 66.0 & 127.0 & 85.5 & 12.7 & Bosnian male & 57.0 & 120.0 & 80.0 & 14.9 \\
\hline Turkish female & 82.0 & 156.0 & 122.5 & 15.8 & Turkish female & 54.0 & 105.0 & 78.7 & 11.1 & Turkish female & 69.0 & 130.0 & 91.2 & 13.7 \\
\hline Turkish male & 104.0 & 163.0 & 132.4 & 11.5 & Turkish male & 67.0 & 90.0 & 80.2 & 6.2 & Turkish male & 60.0 & 113.0 & 84.7 & 10.3 \\
\hline Systole $_{\text {final }}$ & Min & Max & Mean & Std. Dev. & Diastole $_{\text {final }}$ & Min & Max & Mean & Std. Dev. & Heart rate $_{\text {final }}$ & Min & Max & Mean & Std. Dev. \\
\hline Bosnian female & 83.0 & 146.0 & 121.3 & 14.5 & Bosnian female & 58.0 & 93.0 & 75.2 & 8.6 & Bosnian female & 60.0 & 118.0 & 82.4 & 12.2 \\
\hline Bosnian male & 83.0 & 157.0 & 133.2 & 14.7 & Bosnian male & 53.0 & 95.0 & 77.8 & 9.5 & Bosnian male & 61.0 & 98.0 & 80.6 & 8.8 \\
\hline Turkish female & 100.0 & 150.0 & 123.4 & 13.6 & Turkish female & 58.0 & 98.0 & 76.3 & 7.8 & Turkish female & 59.0 & 129.0 & 86.4 & 13.0 \\
\hline Turkish male & 98.0 & 148.0 & 127.7 & 12.5 & Turkish male & 59.0 & 92.0 & 76.5 & 7.2 & Turkish male & 64.0 & 104.0 & 80.5 & 10.5 \\
\hline
\end{tabular}

Table 2: Descriptive statistical result of 4 group blood pressure and heart rate during the exam and non-exam times. 


\begin{tabular}{|c|c|c|c|c|c|c|c|c|c|}
\hline & \multicolumn{3}{|c|}{ Non-Exam days } & \multicolumn{3}{|c|}{ Midterm } & \multicolumn{3}{|c|}{ Final } \\
\hline & Systole & Diastole & Heart rate & Systole & Diastole & Heart rate & Systole & Diastole & Heart rate \\
\hline Bosnian female & 113.8 & 74.9 & 82.3 & $13.2 \%$ & $9.3 \%$ & $8.5 \%$ & $7.0 \%$ & $0.1 \%$ & $0.0 \%$ \\
\hline Bosnian male & 130 & 80.8 & 74.6 & $6.9 \%$ & $6.1 \%$ & $6.6 \%$ & $2.3 \%$ & $3.7 \%$ & $1.3 \%$ \\
\hline Turkish female & 111.9 & 75.3 & 87.4 & $8.9 \%$ & $5.3 \%$ & $4.5 \%$ & $0.7 \%$ & $1.3 \%$ & $1.1 \%$ \\
\hline Turkish male & 126.5 & 76.5 & 81.6 & $4.7 \%$ & $5.3 \%$ & $2.4 \%$ & $0.00 \%$ & $0.0 \%$ & $1.2 \%$ \\
\hline
\end{tabular}

Table 3: Comparison of blood measurement percentage between exam and non-exam days.

the minimum increasing depending on their systole, diastole and heart rate increasing percentage, $4.7 \%, 5.3 \%$ and $2.4 \%$ respectively.

\section{Final week}

The selected students' final week blood pressure and heart rate have been measured and compare with non-exam days data. Although it was expected that the final measurements might have been more than non-exam days or midterm, the fact was not like that. Interestingly, final week blood measurements have shown various values, not just increasing but also decreasing and non-change. As a result of nonexam days and final days ' comparison, while Bosnian females' systole values have increased $7.0 \%$, their diastole and heart rates were almost stable. Another interesting result belongs to the Bosnian males group. Although the all blood values increased during the midterm, they showed various percentages during the final days. Their systole and heart rate just increased $2.3 \%$ and $1.3 \%$, diastole decreased $3.7 \%$. On the other side, Turkish females and males blood measurements have demonstrated almost similar during the final days. While Turkish females' systole, diastole increased $0.7 \%, 1.3 \%$, heart rate decreased $1.1 \%$, and Turkish males' systole, diastole have not changed, heart rate decreased $1.2 \%$ during the final days. Generally, it could be said that Bosnian females blood measurements have the highest increasing, but Turkish males have the lowest increasing or stable profile during the final days. Although it was suggested that final days might have been more increasing values, midterm values had much higher than final days. Actually, the results were quite expected, because of passing course system. If the students fail from final, they have right to take make-up to pass their course. Therefore, final is not so big deal to increase stress level for the students. On the other hand, the midterm results of the students affect the passing grade both for final or make-up exams in same percentages. Thus, midterm results make them the most important exams to pass the course in the university. Finally, it could be concluded that the more stressful the days are the higher the blood pressure and heart rate measurement days.

\section{Correlation significance of the systole, diastole and heart rate}

We aimed to find the potential correlation among the blood measurements result. Thus, the all data were correlated using Pearson's correlation (Significant at the 0.01 level and significance at the level 0.05 ). The high correlation results were over 0.500 Pearson correlation and Significant 0.01 (2-tailed) represented by deep color. The low correlation results were less than 0.500 Pearson correlation and Significant 0.05 (2-tailed) represented by light color. At the end, the all four groups correlations were represented high correlation (deep color) and low correlation (light color) (Figure 1). As descriptive statistics result comparison, Bosnian female correlation values and significance were higher than the other. While 11 high correlation results and 0.722 Pearson value sample belong to Bosnian female, 5 high correlation values and 0.500 Pearson value sample belong to Turkish male.

\section{Bosnian female correlation}

According to the correlation significance 0.01 (2-tailed), 10 high correlated values have been found and represented by deep green (Figure 1). Most of the Bosnian females correlations were between systole/diastole or itself. The highest correlations of the group were systole $3 /$ diastole 3 , systole $2 /$ diastole 2 , systole $1 /$ diastole 1 and systole $1 /$ systole $3,0.722,0.674,0.610$ and 0.591 respectively. The low significance correlations of the group were 0.01 significance (2-tailed) and represented by light green. There were just two low considered correlations which were between systole 1 /systole 2 and systole $1 /$ diastole 2, 0.456 and 0.434 respectively.

\section{Bosnian male correlation}

There were 9 high correlation (significance 0.01) samples in the group and represented by deep blue color (Figure 1). Here are the some prominent examples in this order; systole 2 /systole 3 , heart rate 1 /heart rate 2 , distole 1 /disatole $3,0.698,0.636,0.632$ respectively (Figure 1 ). The lower significance values of the group were presented by light blue color. Diastole $1 /$ diastole 2 , systole 1 /diastole 1 , diastole 2 /systole 3 and heart rate $1 /$ heart rate 3 were the examples of the significance correlations, $0.471,0.468,0.461,0.451$ respectively.

\section{Turkish female correlation}

6 significance correlations results were found in this group and represented by deep yellow color. The highest correlation results have been found between, systole $2 /$ diastole 2 , systole 1 /diastole 1 , diastole 3 /systole $3,0.666,0.621,0.572$ respectively (Figure 1 ). The lower correlations results consisted of diastole 3 /heart rate 3 , diastole 2/ heart rate 3 , diastole $2 /$ systole $3,0.410,0.354,0.351$ respectively and represented by light yellow color.

\section{Turkish male correlation}

Turkish male correlation results included 5 high significance $(0.01)$ and 3 low significance $(0.05)$ values and represented by deep red and light red colors (Figure 1). While systole $3 /$ systole 2 , heart rate 1 /heart rate 2 , diastole 1 /heart rate 1 were the higher significance, $0.609,0.564$, 0.505 , systole $1 /$ systole 3 , diastole $1 /$ diastole 3 , diastole 1 /diastole 2 were the lower significance correlation results $0.318,0.310,0.309$ respectively.

Overall results of the research showed that both Bosnian females and males have high blood pressure during the midterm exams than Turkish students. It had been already supposed that midterm stress would be more than final exam days because of the importance of midterms which affected the passing the course and grades of having high GPA (grade point average). Since Bosnian students blood pressure higher than Turkish, it has been supposed that it was nation specific characteristics, having more stress during the exams. It is the university rule that the scholarship may continue depending on the students' success for the coming years. If the students have scholarship should study more and get high grades from the exams especially midterm. Another rule of the university was scholarship program. It was known that depending on the program, the university just gives scholarship to the Bosnian students not international students. 


\begin{tabular}{|c|c|c|c|c|c|c|c|c|c|c|c|c|c|c|c|c|c|c|c|}
\hline & & Systole 1 & Dias & ole 1 & Heart Rate 1 & Syst & & Diast & & Heart $\mathrm{F}$ & ate 2 & & Systole. & & & astole & & Hear & \\
\hline \multirow{2}{*}{ Systole 1} & Pearson Correlation & & .468 & .621 & & .456 & & .434 & & & & .318 & .591 & & .499 & & & & \\
\hline & Sig.(2-tailed) & & .001 & .000 & & . 001 & & .002 & & & & .024 & .000 & & .000 & & & & \\
\hline \multirow{2}{*}{ Diastole 1} & Pearson Correlation & .610 & & & .505 & & & .309 & & & & & & & .576 & .310 & .632 & & \\
\hline & Sig. (2-tailed) & .000 & & & .000 & & & .029 & & & & & & & .000 & .028 & .000 & & \\
\hline \multirow{2}{*}{ Heart rate 1} & Pearson Correlation & & & & & & & & & .636 & .564 & & & & & & & 588 & .500 \\
\hline & Sig. (2-tailed) & & & & & & & & & .000 & .000 & & & & & & & 000 & .000 \\
\hline \multirow{2}{*}{ Systole 2} & Pearson Correlation & .526 & & & & & & .674 & .666 & & & .540 & 698 & .509 & & & .309 & & \\
\hline & Sig. (2-tailed) & .000 & & & & & & .000 & .000 & & & .000 & .000 & .000 & & & .029 & & \\
\hline \multirow{2}{*}{ Diastole 2} & Pearson Correlation & & .471 & & & & .564 & & & & .319 & .351 & .461 & & 629 & .513 & & & 354 \\
\hline & Sig. (2-tailed) & & .001 & & & & .000 & & & & .024 & .012 & .001 & & .000 & .000 & & & .012 \\
\hline \multirow{2}{*}{ Heart rate 2} & Pearson Correlation & & & & .451 & & & & & & & & & & & & & & \\
\hline & Sig. (2-tailed) & & & & .001 & & & & & & & & & & & & & & \\
\hline \multirow{2}{*}{ Systole 3} & Pearson Correlation & .540 & & & & .540 & .609 & & & & & & & & 630 & .482 & .722 & & \\
\hline & Sig. (2-tailed) & .000 & & & & .000 & .000 & & & & & & & & .000 & .000 & .000 & & \\
\hline \multirow{2}{*}{ Diastole 3} & Pearson Correlation & & & .282 & & & & & & & & & & .572 & & & & 57 & 410 \\
\hline & Sig. (2-tailed) & & & .047 & & & & & & & & & & .000 & & & & .000 & .003 \\
\hline \multirow{2}{*}{ Heart rate 3} & Pearson Correlation & & & & .451 & & .324 & & .403 & .519 & & & & & & & & & \\
\hline & Sig. (2-tailed) & & & & .001 & & .022 & & .004 & .000 & & & & & & & & & \\
\hline
\end{tabular}

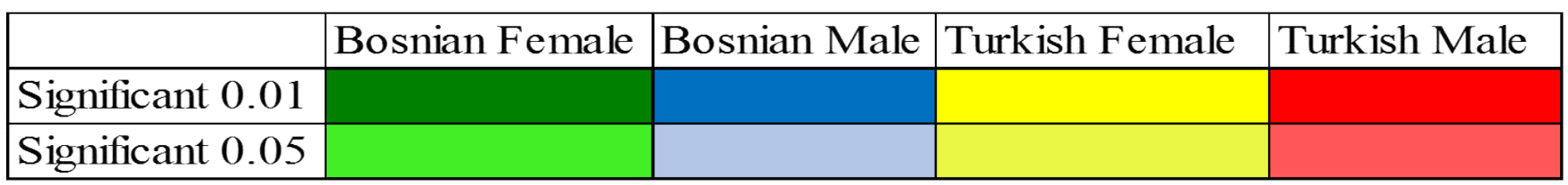

The correlation results: While 0.01 significant data were presented in deep color, 0.05 level significant data were presented in light color. Yellow represents Turkish female students, red Turkish male students, blue Bosnian male students and green Bosnian female students. At the end of all results we wanted to see any correlation between high blood pressure result and the groups. Although it could be asked different questions, such as smoking, high fat diet, sport activity, we just asked one question whether the student has scholarship loosing anxiety or not to see the potential effects on the measurement result. The survey question correlation was given at the end of result.

Figure 1: Correlation significance among the groups.

Therefore, the scholarship anxiety only belongs to Bosnian students. In order to understand the relation between having scholarship and exam stress, we asked a question to the selected Bosnian students whether they had a scholarship or not. Since the selected Turkish students have no scholarship, the question did not ask for them. As a result of the question to the students, we got $95 \%$ of the female and $90 \%$ of the Bosnian students had a scholarship. It was a quite good explanation that it was a good relation between the students and exam stress. It should be emphasized one more time that midterm results affect to the overall GPA more than the final. Therefore, the students must keep midterm result as much as high to get high GPA average.

\section{Discussion}

Stress is the side effects of our daily life, even sometimes we don 't understand the reason, but we have. It is quite obvious that special days increase our stress amount and physiological homeostasis. Moreover, thinking of the special days is enough to stimulate our mind to increase the stress. Too much or less stress could be a reason of the unsuccessful result. Thus, human should regulate the stress depending on the situation. A special day and stress relation is easily observed in students' life, especially exam days. Many students may be unsuccessful just because of the high level of the stress or could be other reasons to keep the stress at high level. Since the university students get their diploma, scholarship opportunity, acceptance by companies or other universities after graduation, they all need high grades from their courses. Therefore, the anxiety of grades and GPA are the main obstacles to cope with them. Although the same type stress makes similar effects for the male or female, it is clear that females are affected more than males by any kind of stress or males manage the stress condition better than females. Measurement of blood pressure is a just result which shows psychologic and physiological relation. The knowledge presents either females are more emotional or males are more successful to manage the stress. Another important and clear observation is student behavior about exams. When the students think, or prepare for the exams, they have more stress than doing exams. This is also another clear observation which can give us some information about stress and its characteristics.

\section{References}

1. Ogedegbe G, Pickering $T$ (2010) Principles and techniques of blood pressure measurement. Cardiol Clin 28: 571-586. 
Citation: Dogan S, Nalcaci N, Dogan S, Badnjevic A, Kurtovic A, et al. (2017) Changes in Blood Pressure and Heart Rate Measurement Undergraduate Students During Exam Period. J Biom Biostat 8: 347. doi: 10.4172/2155-6180.1000347

2. Florence L, Banik U, Basanti N, Pricila TH, Devi MA (2014) Effect of PreExamination Stress on Blood Pressure and Pulse Rate of Undergraduate Medical Students. Journal of Dental and Medical Sciences (IOSR-JDMS) 13 101-103.

3. Kathrotia R, Kakaiya M, Parmar D, Vidja K, Sakariya K, et al. (2010) Variable Response Of Ist Mbbs Students To Exam Stress. NJIRM 1: 23-27.

4. Thakur D, Oomen ER (2015) Effect of examination stress on physiological and psychological parameters among undergraduate medical students.

5. Sharma B, Wavare R, Deshpande A (2011) A study of academic stress and its effect on vital parameters in final year medical students at SAIMS Medical College, Indore, Madhya Pradesh. Biomedical Research 22: 361-365.

6. Shah SJ, Patel HM (2014) Effect of Examination Stress on Parameters of Autonomic Functions in Medical Students. International Journal of Science and Research (IJSR)

7. Dogan S, Kurtovic-Kozaric A, Karli G (2016) The Detection of Extremely High and Low Expressed Genes by EGEF Algorithm in Invasive Breast Cancer. $J$ Biom Biostat 7: 286.
8. Dogan S, Kurtovic-Kozaric A, Hajrovic A, Lisic M, Gokgoz E (2016) Comparison of MLL Fusion Genes Expression among the Cytogenetics Abnormalities of Acute Myeloid Leukemia and Their Clinical Effects. J Biom Biostat 7: 312.

9. Dogan S, Cilic A, Kurtovic-Kozaric A, Ozturk F (2015) Detection of G-type density in promoter sequence of colon cancer oncogenes and tumor suppressor genes. Bioinformation 11: 290-295.

10. Dogan S, Kurtovic-kozaric A (2015) Changes of Molecular, Cellular and Biological Activities According to microRNA-mRNA Interactions in Ovarian Cancer. Computational Molecular Biology.

11. Takatsuji K, Sugimoto $Y$, Ishizaki S, Ozaki $Y$, Matsuyama E, et al. (2008) The effects of examination stress on salivary cortisol, immunoglobulin $A$, and chromogranin A in nursing students. Biomed Res 29: 221-224.

12. Johansson GG, Laakso ML, Peder M, Karonen SL (1988) Examination stress decreases plasma level of luteinizing hormone in male students. Psychosom Med 50: 286-294.

13. Lucini D, Norbiato G, Clerici M, Pagani M (2002) Hemodynamic and autonomic adjustments to real life stress conditions in humans. Hypertension 39: 184-188. 